\title{
Preliminary study on blend based mixed ion- electron conductor- (PVA: PVK): $\mathrm{CH}_{3} \mathrm{COONH}_{4}$ : EC system
}

\author{
Shanker Lal Agrawal ${ }^{1}$, Rajendra Prasad Kumhar ${ }^{2}$ \\ ${ }^{1}$ SSI Laboratory Department of Physics, A P S University, Rewa India \\ ${ }^{2}$ Department of Physics, Govt. Maharaja College, Chhatarpur India
}

Email address:

sla_ssi1956@rediffmail.com (S. L. Agrawal), rpk1972ssi@gmail.com (R. P. Kumhar)

To cite this article:

Shanker Lal Agrawal, Rajendra Prasad Kumhar. Preliminary Study on Blend Based Mixed Ion- Electron Conductor- (PVA: PVK): $\mathrm{CH}_{3} \mathrm{COONH}_{4}$ : EC System. International Journal of Materials Science and Applications. Vol. 3, No. 4, 2014, pp. 129-136. doi: $10.11648 /$ j.ijmsa.20140304.12

\begin{abstract}
An attempt has been made in the present work to develop blend based mixed ion-electron conductor viz. PVA: PVK: $\mathrm{CH}_{3} \mathrm{COONH}_{4}$ : $\mathrm{EC}$ system. Formation of polymer blend and composite has been evidenced during XRD and IR studies. Ionic conductivity of this system is seen to improve by an order of magnitude at room temperature with optimum at $1.27 \times 10^{-3}$ $\mathrm{S} / \mathrm{cm}$ for 0.4 mole ammonium acetate concentration. Ionic charge transport seems to dominate as reflected from I-t measurements. Temperature dependent conductivity shows that ionic conduction is controlled by combination of Arrhenius and VTF behavior. AC conductivity behavior is seen to be dictated by Jonscher Power law.
\end{abstract}

Keywords: PVA: $\mathrm{PVK}$ Blend, $\mathrm{CH}_{3} \mathrm{COONH}_{4}$, $\mathrm{PVK}$ Based Electrolyte, Ion- Electron Conductor, Polymer Composite Electrolyte

\section{Introduction}

In all the emerging technologies like computers, communication devices, industrial controls, electric vehicles, laboratory equipments, medical appliances etc. there is an exclusive demand for long life, environmentally friendly, low cost, reliable rechargeable batteries with high specific energy power [1-3]. Within this frame-work, electrode materials - a key component of all electrochemical devices have been widely investigated for application in batteries. In electrochemistry, an electrode is an electronic conductor in contact with ionic conductor through which charge transfer reactions take place. This electronic conductor can be a metal, or a semiconductor, or a mixed ionic-electronic conductor. Metal electrodes usually suffer from several serious drawbacks, like high reactivity with electrolyte, long life, non- safety in ambient environment etc. Nevertheless, these shortcomings have been greatly reduced in recent years through the use of intercalating layered materials as electrodes. Few widely used electrode materials reported in literature are $\mathrm{LiCoO}_{2}, \mathrm{LiCo}_{\mathrm{x}} \mathrm{Ni}_{1-\mathrm{x}} \mathrm{O}_{2}, \mathrm{LiMn}_{2} \mathrm{O}_{4}, \mathrm{~V}_{2} \mathrm{O}_{5}, \mathrm{~V}_{3} \mathrm{O}_{8}, \mathrm{LiFePO}_{4}$ as cathode and $\mathrm{LiC}_{6}, \mathrm{Li}_{3-\mathrm{x}} \mathrm{Co}_{\mathrm{x}} \mathrm{N}, \mathrm{KC}_{8}, \mathrm{SnO}_{2}, \mathrm{Li}_{3} \mathrm{Sb}$ as anode [4].

Beside these intercalating materials, mixed conducting materials have shown promise because of their mixed conduction mechanism and their possible application in electrochemical devices, such as assisted interfacial ion transport between electrolyte and electrodes [2]. In the category of mixed conductors, polymer membrane possessing such properties has shown promise [5, 6]. Mixed ionic-electronic conducting polymeric materials can be prepared by incorporating mobile ion and an electronic donor/ acceptor species in a polymer host. In recent years, researchers have reported mixed conducting materials such as poly (methoxyethoxy ethoxyphosphazene) - $\mathrm{NaI}_{n}$ and PEO-NaI 3 [5, 7], blends of polypyrrole and PEO [6, 8], PEO-NaSCN-polythiocyanogen $(\mathrm{SCN})_{\mathrm{x}}$ blend [9]. Electrical conductivity was reported earlier to be essentially ionic in the amorphous polyiodide system and electronic in the crystalline complex. Recently, Polyvinyl Carbazole (PVK) - a carbazole derivative of poly vinyl chloride (PVC) (carbazole group has substituted chlorine atom) has also been looked upon as a probable candidate for development of electrodes and stiffener in polymer electrolytes [10]. Introduction of PVK in polymer electrolyte is expected to improve the electrical conductivity of the system besides improving mechanical strength of electrolyte and the interfacial properties between the electrode \& electrolyte [11]. With these facts in mind, an attempt has been made in the present work to prepare a mixed 
ion electron conducting polymer system by incorporating PVK in PVA based electrolyte system (an ionic system), namely, PVA: $\mathrm{CH}_{3} \mathrm{COONH}_{4}$ : $\mathrm{EC}$ system and characterize their films using XRD, FTIR, Optical Microscopy, electrochemical and electrical measurements.

\section{Experimental}

PVA (average molecular weight 124,000- 186,000 Aldrich make), PVK (average molecular weight 40,000 Aldrich make), ammonium acetate $\left(\mathrm{CH}_{3} \mathrm{COONH}_{4}\right)$, AR grade sd fine chem make and aprotic solvent dimethyl sulphoxide (DMSO) Merk make, were used for synthesis of mixed electron ionic conductor. Firstly both polymers PVA and PVK were dissolved in DMSO in the ratio (PVA: PVK) of $90: 10$ and stirred for $3 \mathrm{~h}$ at $50^{\circ} \mathrm{C}$ to obtain homogeneous mixing. In the next step an appropriate quantity of ammonium acetate $\left(\mathrm{CH}_{3} \mathrm{COONH}_{4}\right)$ salt in $\mathrm{EC}$ (Aldrich make) was added to the above mixture and stirred further for $2 \mathrm{~h}$ to complete homogenous mixing. The final solution was poured in a poly carbonate pettri dish to obtain thick films of mixed conducting system. XRD measurements of as synthesized samples were carried out on RIGAKU JAPAN MINIFLEX-II in the range $2 \theta=5^{\circ}$ to $70^{\circ}(=1.5406$ Á) for complexation studies. FTIR spectra were recorded on Nicolet iS10 spectrophotometer in the range 4000- 500 $\mathrm{cm}^{-1}$ to evaluate interaction among components leading to formation of composite system. Morphological behavior of as synthesized composite films was studied using optical polarizing microscope (Carl Ziess- Germany model HAL-100). C-V and I-t measurements were performed on a $\mathrm{CH}$ - electrochemical workstation $(\mathrm{CH}$ instruments model $\mathrm{CH608)}$ to determine electrochemical window and nature of charge transport. Electrical characterization of the material was carried out using impedance spectroscopy technique. Complex impedance parameters were measured with a Hioki impedance analyzer (model 3520) in the frequency range $40 \mathrm{~Hz}-100 \mathrm{KHz}$ using platinum electrodes for electrical contact.

\section{Results \& Discussion}

\subsection{XRD Studies}

Figure 1 depict the XRD pattern of DMSO casted PVA, PVK, PVA: PVK and (PVA: PVK): $\mathrm{CH}_{3} \mathrm{COONH}_{4}$ : EC complex for different salt concentrations. A relatively sharp characteristic diffraction peak at $2 \theta=22.09^{\circ}$ and a broad peak around $16.7^{0}$ in DMSO casted PVK (diffractogram b) and one peak around $2 \theta=19.6^{\circ}$ in XRD pattern of DMSO casted PVA (curve a) is seen. The observed value for DMSO casted PVA film corresponds to earlier reports [12]. Similarly the characteristic reflections for DMAO casted PVK are close to the observations of $[13,14]$. The slight deviation in results is possibly due to variation in solvent swollen nature of PVK in different organic solvents. When PVK is admixed in PVA to form PVA: PVK blend, the diffraction peaks of both polymers shift towards higher $2 \theta$ value $\left(19.45^{0}\right.$ and $\left.24.23^{0}\right)$ as a consequence of interaction among components leading to formation of a new material viz. polymer blend. Further on, the observed peaks of blend system shift towards lower $2 \theta$ values when $\mathrm{CH}_{3} \mathrm{COONH}_{4}$ salt is added in PVA: PVK blend. This too results from interaction between polymer components and salt. Recently, PVA has been shown to complex with ammonium salts [12, 15-17]. Thus the shifting of diffraction peak can be correlated to formation of blend based complex. Beside these two peaks, few other peaks were also observed in the composite system around $26.9^{0}$, $27.2^{0}, 30.6^{0}, 35.2^{0}, 41.1^{0}$ and $47.6^{0}$. Since these peaks are not assignable to pristine components formation of a new material viz. blend based electrolyte system is thus affirmed. Further on increasing the salt content in the system, all existing peaks suppress excluding the sharp peak at $2 \theta=$ $24.19^{\circ}$ and a shoulder at $2 \theta=18.91^{\circ}$. This is the signature of improvement in morphology of system with increasing salt content.

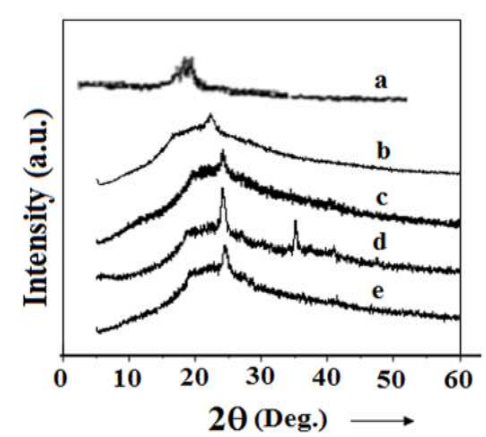

Figure 1. X-ray diffractograms of DMSO casted (a) PVA, (b) PVK and (PVA: $\mathrm{PVK}$ ): $\mathrm{CH}_{3} \mathrm{COONH}_{4}:$ EC containing (c) 0, (d) 0.4 and (e) 0.6 mole of $\mathrm{CH}_{3} \mathrm{COONH}_{4}$ salt respectively.

\subsection{Optical Microscopy}

Optical micrographs of PVA, PVK and (PVA: PVK): $\mathrm{CH}_{3} \mathrm{COONH}_{4}$ : EC complex for different salt concentration are shown in figure $2(\mathrm{a}-\mathrm{f})$. In the optical image of pure PVA: DMSO film (figure $2 \mathrm{a}$ ) the dark regions symbolise the presence of porous structure - a feature well known [18]. Though the surface is uniform in physical appearance, the pores are heterogeneously distributed in the microstructure. On the average, the pore size of $1.4 \mu$ was estimated in the films which reflect relativity poor solvent retention capability. The appearance of pores might be due to the interconnected network of polymer which are created due to solvent evaporation. Pure PVK film (figure 2b) reflects channel type structure with existence of intermittent pores. However the pore size was found to be smaller in comparison to that of pure PVA film casted in DMSO. When PVK was added to PVA to form a blend its optical image exhibits poor compatibility among polymer components with the presence of rough surface morphology (figure 2c). However the dark regions indicative of pores reduce barring a few pores of big size (figure $2 \mathrm{~d}$ ) in comparison to that of 
pristine components. The morphology of film smoothens out with increasing salt content indicating significant improvement in film morphology and compatibility. When the salt concentration exceeds $0.6 \mathrm{M}$ (fig 2f) in the composite system voids bigger in size start reappearing. This feature is probably on account of salt segreggation. This suggests that optimum salt content is limited to $0.6 \mathrm{M}$ in the blend electrolyte used for investigation.
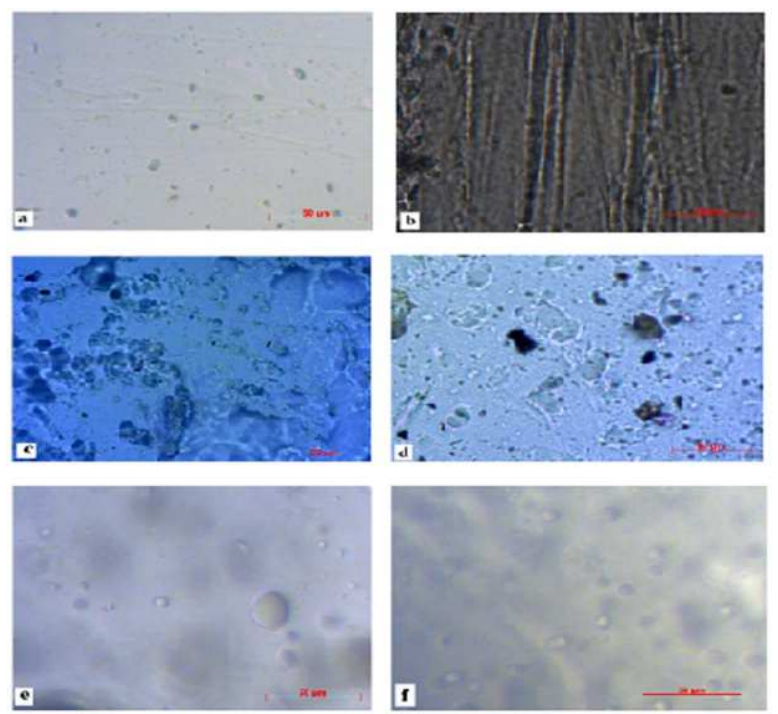

Figure 2. Optical Micrographs DMSO casted (a) PVA, (b) PVK and (PVA: PVK): $\mathrm{CH}_{3} \mathrm{COONH}_{4}$ : EC containing (c) 0, (d) 0.4, (e) 0.6 and (f) 0.8 mole of $\mathrm{CH}_{3} \mathrm{COONH}_{4}$ salt respectively.

\subsection{FTIR Studies}

Figure 3(a-g) shows the FTIR spectra of $\mathrm{CH}_{3} \mathrm{COONH}_{4}$, PVA, PVK, and PVA: PVK and PVA: PVK: $\mathrm{CH}_{3} \mathrm{COONH}_{4}$ : EC mixed ion- electron conductor films prepared in DMSO. In PVA a clear broad band was observed at $3292 \mathrm{~cm}^{-1}$ corresponding to $-\mathrm{OH}$ stretching $(-\mathrm{OH})$ and $\mathrm{CH}$ stretch (symmetric and sub methyl) vibration. This peak is noticed to shift to lower wave number with diminishing intensity in PVA: PVK blends and as well as MIECs with higher salt content. The peaks assignable to $\mathrm{CH}_{3}$ symmetric and $\mathrm{C}-\mathrm{H}$ symmetric vibrations appear in PVA around $2949 \mathrm{~cm}^{-1}$ \& $2906 \mathrm{~cm}^{-1}$ and in PVK around $2922 \mathrm{~cm}^{-1} \& 2854 \mathrm{~cm}^{-1}$ respectively in figure $3(\mathrm{~b}-\mathrm{c})$. These peaks are found in PVA: PVK blend at $2949 \mathrm{~cm}^{-1} \& 2902 \mathrm{~cm}^{-1}$ while in MIECs they appear at $2917 \& 2852 \mathrm{~cm}^{-1}$ for 0.2 molar salt concentration $2943 \mathrm{~cm}^{-1} \& 2869 \mathrm{~cm}^{-1}$ for 0.4 molar $\mathrm{CH}_{3} \mathrm{COONH}_{4}$ and $2946 \mathrm{~cm}^{-1}$ for samples containing 0.6 mole salt. The changes in intensity and shift of these bands indicate interaction among components leading to formation of composite electrolyte system. The peaks around $2241 \mathrm{~cm}^{-1}$ and 1735 $\mathrm{cm}^{-1}$ in PVK related to $\mathrm{C}-\mathrm{N}$ stretch vibration and $\mathrm{C}=\mathrm{O}$ bond respectively remain approximately same (only marginal shift) to indicate partial compatibility in the blend system. However $2241 \mathrm{~cm}^{-1} \mathrm{C}-\mathrm{N}$ related peak in PVK vanishes in composite system due to interaction of salt with polymer. The presence of $\mathrm{C}=\mathrm{O}$ related absorption peak has also been previously reported [19] in PVA: DMSO films and correlated to oxidation of PVA in presence of DMSO. However these peaks are shifted to $2242 \mathrm{~cm}^{-1} \& 1734 \mathrm{~cm}^{-1}$ in PVA: PVK: DMSO blend and $2357 \mathrm{~cm}^{-1} \& 1732 \mathrm{~cm}^{-1}$ respectively in mixed conducting system. This shows enhanced compatibility of polymers in the presence of salt. Moderately intense peak at $1807 \mathrm{~cm}^{-1}$ related to $v-\mathrm{CH}$ vibration in vinyl compounds and in PVA: PVK seem to disappear in mixed conducting system due to interaction of salt with PVA and PVK. Absorption peak at $1600 \mathrm{~cm}^{-1}$ in PVA and at $1559 \mathrm{~cm}^{-1}$ in PVK is also observed in PVA: PVK blend and as well as in mixed conducting system but with lower intensity. It is essentially due to the presence of pseudo absorbed water or water formed during interaction of PVA with DMSO which once again ascertains the observations regarding oxidation of PVA in the presence of DMSO [19]. Moreover, existence of this absorption can also be correlated to the presence of $\mathrm{C}=\mathrm{C}$ group in PVA as conjugated end group or non hydrolizble vinyl acetate group $[20,21]$. Interestingly $\mathrm{CH}_{3}>\mathrm{CH}_{2}$ deformation vibration observed in PVA at $1450 \mathrm{~cm}^{-1}$ and ring vibration of vinyl carbazole moeity in PVK at $1452 \mathrm{~cm}^{-1}$ shifts to higher wave number upon blending $\left(1458 \mathrm{~cm}^{-1}\right)$ and as well as in electrolyte system (1471 $\mathrm{cm}^{-1}$ for $0.6 \mathrm{M}$ salt concentration) as a consequence of interaction among pristine components.

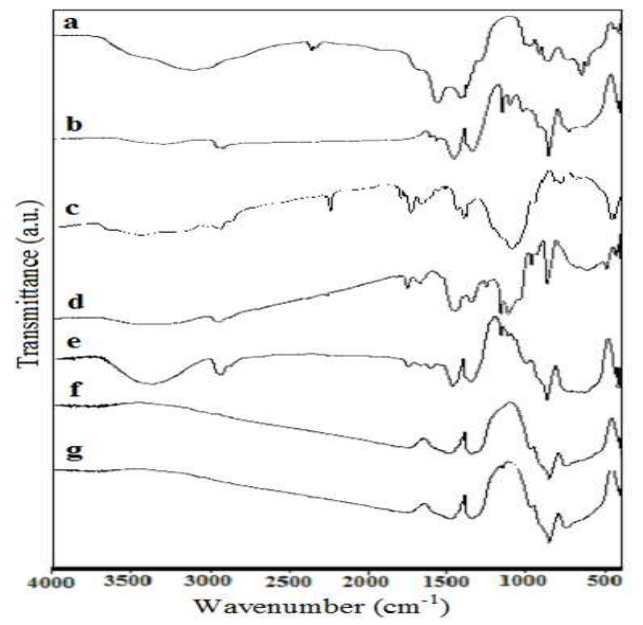

Figure 3. IR spectra of (a) $\mathrm{CH}_{3} \mathrm{COONH}_{4}, \mathrm{DMSO}$ casted (b) $\mathrm{PVA}$, (c) $\mathrm{PVK}$ and (PVA: $\mathrm{PVK}$ ): $\mathrm{CH}_{3} \mathrm{COONH}_{4}$ : EC containing (d) 0 , (e) 0.2 , (f) 0.4 and (g) 0.6 mole of $\mathrm{CH}_{3} \mathrm{COONH}_{4}$ salt respectively.

Likewise $1332 \mathrm{~cm}^{-1}$ absorption corresponding to $-\mathrm{OH}$ bend in PVA, $\mathrm{CH}$ in plane deformation vibration of vinylidene group in presence of DMSO in PVK at $1347 \mathrm{~cm}^{-1}$ and $1378 \mathrm{~cm}^{-1}, 1341 \mathrm{~cm}^{-1}, 1300 \mathrm{~cm}^{-1}$ vibration in $\mathrm{CH}_{3} \mathrm{COONH}_{4}$ salt appear at higher wave numbers in the composite system $\left(1391 \mathrm{~cm}^{-1}, 1336 \mathrm{~cm}^{-1}\right.$ and $1303 \mathrm{~cm}^{-1}$ for $0.6 \mathrm{M}$ salt concentration) due to interaction of salt with polymers leading to formation of their complexes. $\mathrm{CH}$ in plane deformation of aromatic ring related to PVK at 1050 $\mathrm{cm}^{-1}$ is seen to vanish both in PVA: PVK blend and as well as composite electrolytes. Likewise skeletal asymmetric $\mathrm{CH}$ rocking vibration in PVA: DMSO film at $915 \mathrm{~cm}^{-1}$ and PVK: DMSO film at $914 \mathrm{~cm}^{-1}$ are seen to move towards higher 
wave number when composite system is formed. Similarly $\mathrm{CH}$ rocking vibration of PVA $\left(722 \mathrm{~cm}^{-1}\right)$ and PVK $\left(744 \mathrm{~cm}^{-1}\right)$ appear in PVA: PVK blend at $720 \mathrm{~cm}^{-1}$ and in composite system at $729 \mathrm{~cm}^{-1}\left(0.2 \mathrm{M}\right.$ salt), $745 \mathrm{~cm}^{-1}(0.4 \mathrm{M}$ salt) and 748 $\mathrm{cm}^{-1}(0.6 \mathrm{M}$ salt $)$ respectively which gives signature of enhanced compatibility in blends in the presence of salt. In view of all these observations it is envisaged that strong interaction takes place between polymer components in the presence of salt leading to formation of composite ion electron conducting system.

\subsection{I-T Studies}

Amperometric I-t technique was used to assess the nature of ion transport and evaluate total ionic transference number from current time plot with platinum electrodes. The variation of current with time for mixed conducting samples is shown in figure 4. Polarization behavior is reflected in all these curves. The initial current $i_{\text {initial }}$ and final current $i_{\text {final }}$ was noted from the polarization curves and the total ionic transference number $t_{\text {ion }}$ was calculated using the relation:

$$
t_{\text {ion }}=\frac{i_{\text {initial }}-i_{\text {final }}}{i_{\text {initial }}}
$$

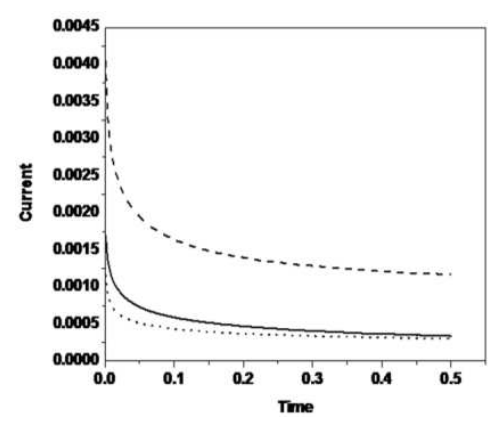

Figure 4. I-t polarization curve of DMSO casted (PVA: PVK): $\mathrm{CH}_{3} \mathrm{COONH}_{4}$ : EC containing (solid line) 0.2 , (---) 0.4 and (...) 0.6 mole of $\mathrm{CH}_{3} \mathrm{COONH}_{4}$ salt respectively.

The calculated values of $t_{\text {ion }}$ for different composite films varies from 0.8 to 0.7 with varying molar concentration of salt which ascertains dominance of ionic charge transport over electronic transport in mixed conducting system.

\subsection{Studies}

A stable potential window is of great practical importance for applications of electrolyte materials in batteries and super capacitors [22]. Figure 5(a-e) compares the cyclic voltagrams of PVA: PVK and (PVA: $\mathrm{PVK}$ ): $\mathrm{CH}_{3} \mathrm{COONH}_{4}$ : $\mathrm{EC}$ systems. It is apparent from this figure that electrochemical stability is moderately poor in PVA: PVK blend $(-1 \mathrm{~V}$ to $+1 \mathrm{~V})$. On addition of salt, this stability is seen to improve significantly ranging from $-1.5 \mathrm{~V}$ to $1.6 \mathrm{~V}$. An interesting observation is the appearance of a step change around $+1.2 \mathrm{~V}$ and $-0.5 \mathrm{~V}$ during oxidation and reduction cycles respectively. During cyclic voltametry of PVA: DMSO film an oxidation related broad peak is observed (voltagram a) at $+1 \mathrm{~V}$. Oxidation of PVA in presence of DMSO has been envisaged earlier [19]. This voltagram clearly reasserts the observation made by them. The step change during anodic cycle at $+1.0 \mathrm{~V}$ also shows oxidation of PVA: PVK blend in the presence of DMSO solvent which smoothens out upon addition of salt to form composite system. A single prominent oxidation/reduction peak for composite system is noticed in cyclic voltametry for all electrolyte systems, around $-1 \mathrm{~V}$ and $+0.23 \mathrm{~V}$ which is possibly due to $\mathrm{NH}_{4}^{+}$ions that contributes to ionic conduction. Comparison of $\mathrm{C}-\mathrm{V}$ data indicates best cyclic reversibility for composite system containing $0.4 \mathrm{M}$ salt with optimum improvement in electrochemical stability. Electrochemical window has been found to range from $-0.366 \mathrm{~V}$ to $+1.633 \mathrm{~V}$.

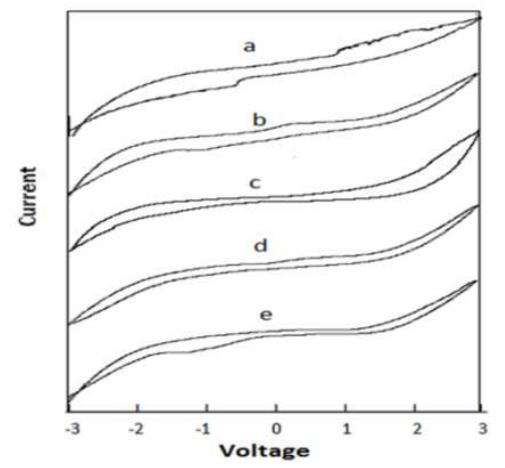

Figure 5. Cyclic voltagrams of DMSO casted (PVA: $\mathrm{PVK}$ ): $\mathrm{CH}_{3} \mathrm{COONH}_{4}$ : $E C$ containing (a) 0, (b) 0.2 , (c) 0.4, (d) 0.6 and (e) 0.8 mole of $\mathrm{CH}_{3} \mathrm{COONH}_{4}$ salt respectively.

\subsection{Electrical Conductivity - Salt Concentration Dependence}

The variation of ionic conductivity of liquid electrolyte $\mathrm{CH}_{3} \mathrm{COONH}_{4}$ : DMSO and (PVA: PVK): $\mathrm{CH}_{3} \mathrm{COONH}_{4}$ : EC system as a function of salt concentration is shown in figure 6 .

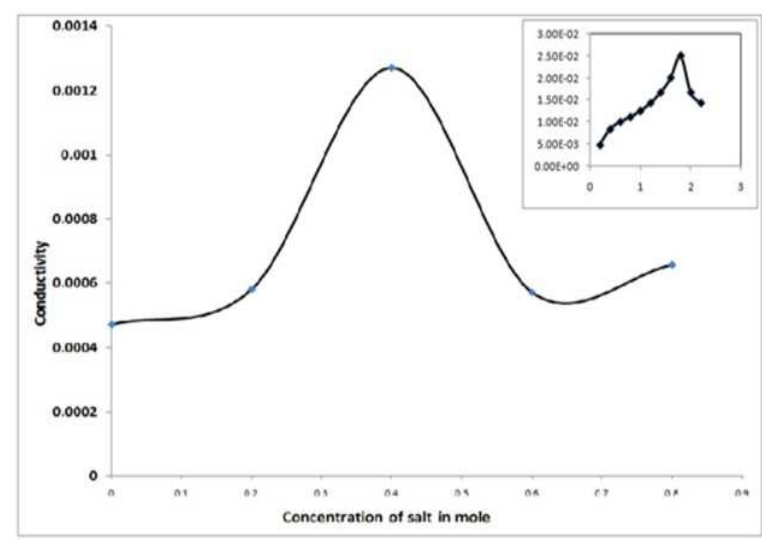

Figure 6. Ionic conductivity of (PVA: $\mathrm{PVK}): \mathrm{CH}_{3} \mathrm{COONH}_{4}$ : EC at different mole of Ammonium acetate salt. Inset shows the ionic conductivity of $\mathrm{CH}_{3} \mathrm{COONH}_{4}: \mathrm{DMSO}$ liquid electrolyte at different mole.

The conductivity of composite system has been extracted with the help of Cole- Cole plot (figure 7a). The conductivity of liquid electrolyte is seen to rise with increasing salt concentration and reach an optimum at $2.5 \times 10^{-2} \mathrm{Scm}^{-1}$ for $1.8 \mathrm{M}$. The behavior of liquid electrolyte can be best 
described by the well- known Walden's rule [23]. Dimethyl sulfoxide is highly aprotic solvent and ammonium acetate is likely to dissociate into respective ions in the solution [24] which in turn gives rise to its electrical conductivity. The initial increase in electrical conductivity can be related to significant increase in the number of ions as a result of dissociation of ion pairs which increases the concentration of free ions. The dissociation of ion pairs is not constant at all concentration rather it decreases with increasing salt concentration. As a consequence, un-dissociated ion pair aggregates do not respond to applied electric field [25] and so conductivity attain an optimum. Beyond this value a significant fall in conductivity is noticed. This fall in conductivity is due to increase in viscosity of the system, which reduces the mobility of carriers according to Walden's rule. While performing impedance spectroscopy on PVA: PVK: $\mathrm{CH}_{3} \mathrm{COONH}_{4}$ system only low frequency spikes attributed to double layer response at electrode-electrolyte interface were visible [26] with an intercept on real $\mathrm{z}$ axis (figure 7a). Intercept value was used to evaluate bulk conductivity of polymeric system. From the conductivity data it is apparent that conductivity of PVA: PVK: $\mathrm{CH}_{3} \mathrm{COONH}_{4}$ system increases only up to 0.4 mole concentration of ammonium acetate before diminishing rapidly. In addition, conductivity values have been found to be low in comparison to liquid electrolyte.

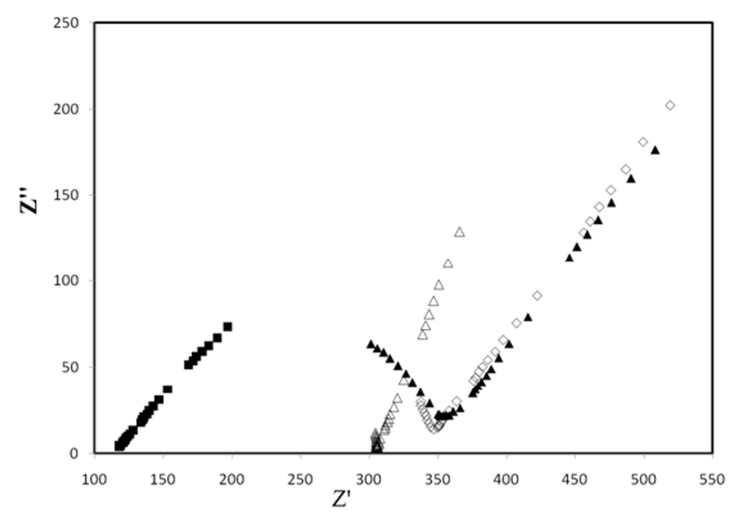

Figure 7a. Cole- cole plots of (PVA: $\mathrm{PVK}): \mathrm{CH}_{3} \mathrm{COONH}_{4}$ : EC containing

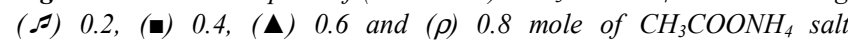
respectively.

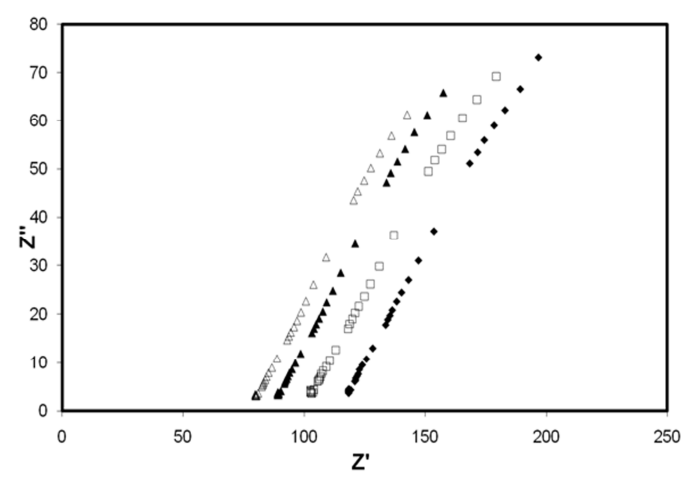

Figure 7b. Cole-cole plots of (PVA: $\mathrm{PVK}): \mathrm{CH}_{3} \mathrm{COONH}_{4}:$ EC at 0.4 mole of Ammonium acetate salt for $\left(\mathrm{B}_{3}\right) 35,(\square) 45,(\mathbf{\Lambda}) 60$ and $(\rho) 70$ degree celsius temperature.
At lower concentrations, full dissociation of salt into respective ions may be considered and there is nothing to be dissociated by polymer. FTIR studies suggest strong interaction among polymer components and salt which promote greater dissociation of salt leading to enhancement in charge carrier concentration. Therefore, initially as the concentration of salt enhances, concentration of free ions increases significantly. Also XRD studies have shown enhancement in amorphous nature of films which in turn affects mobility positively. Both these factors coupled together therefore cause significant change in over all conductivity in accordance with the relation:

$$
\sigma=n q \mu
$$

where $q$ represents the charge of mobile carrier, $\mathrm{n}$ the charge carrier concentration and $\mu$ the carrier mobility. Alternately enhancement in conductivity can also be understood with the help of breathing chain model [3] according to which dissociation of ion pairs is assisted by breathing of polymer chain and so charge concentration variation described above comes into play. A sharp fall in ionic conductivity of PVA: PVK: $\mathrm{CH}_{3} \mathrm{COONH}_{4}$ system can be understood in the following way.

As said earlier, charge carrier concentration $n$ in liquid electrolyte (figure 6) goes on increasing due to dissociation of salt till $1.8 \mathrm{M}$ salt concentration which raises its conductivity. This number of charge carriers depends upon the acidity constant (or dissociation energy involved) and dielectric constant $\varepsilon$ as

$$
n \propto \exp \left(-\frac{U}{\varepsilon k T}\right)
$$

In the present investigation, it has been found that $\varepsilon$ decreases significantly (figure 8) beyond $0.4 \mathrm{M}$ salt content in the mixed system. Also ionic salt aggregates are apparent in optical view graphs beyond this concentration. These factors cause a decrease in charge carrier concentration $(n)$ and so in ionic conductivity in accordance with expression 3. Another possibility for decrease in ionic conductivity can be associated to existence of tortuous pathways for ion migration and formation of ion agglomerates.

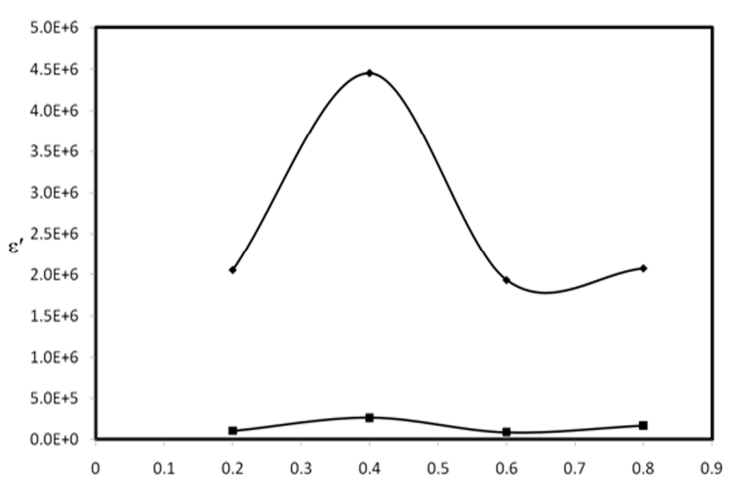

Figure 8. Variation of dielectric permittivity with Ammonium acetate $\left(\mathrm{CH}_{3} \mathrm{COONH}_{4}\right.$ ) salt concentration for (a) $100 \mathrm{~Hz}$ and (a) $1000 \mathrm{~Hz}$. 


\subsection{Temperature Dependence of Conductivity}

It is clear from Cole- Cole plot of PVA: PVK: $\mathrm{CH}_{3} \mathrm{COONH}_{4}$ system that there is a continuous drop in bulk resistance of composite system with increase of temperature (figure $7 \mathrm{~b}$ ). Hence temperature dependence of electrical conductivity of (PVA: $\mathrm{PVK}$ ): $\mathrm{CH}_{3} \mathrm{COONH}_{4}$ : EC system at different salt concentration was studied and the result have been shown in figure 9. The variation of conductivity indicates that the conductivity increases with rise in temperature with two distinct straight lines separated by a region in which there a non- linear change in conductivity value. At low temperature (around room temperature) the conductivity response is essentially dictated by the trapped liquid electrolyte within the polymer matrix and hence Arrhenius behavior is noticeable. However, as the temperature approaches the glass transition temperature of blend PVA: PVK $\left(65^{\circ} \mathrm{C}\right)$ in polymer composite system, the matrix becomes flexible giving rise to conductivity response associated to that PVA: PVK: $\mathrm{CH}_{3} \mathrm{COONH}_{4}$ electrolyte. Therefore, as the temperature is raised, further the conductivity enhancement is best described by VTF relationship. Again a sharp change in electrical conductivity is noticed when the temperature approaches a value corresponding to glass transition temperature of PVA viz. $85^{\circ} \mathrm{C}$. Beyond this temperature liquid like Arrhenius behavior once again dominates. Similar behavior is seen for all salt molar concentrations and so the temperature dependence of conductivity can be well correlated to combination of Arrhenius and VTF type relationship described by the expression:

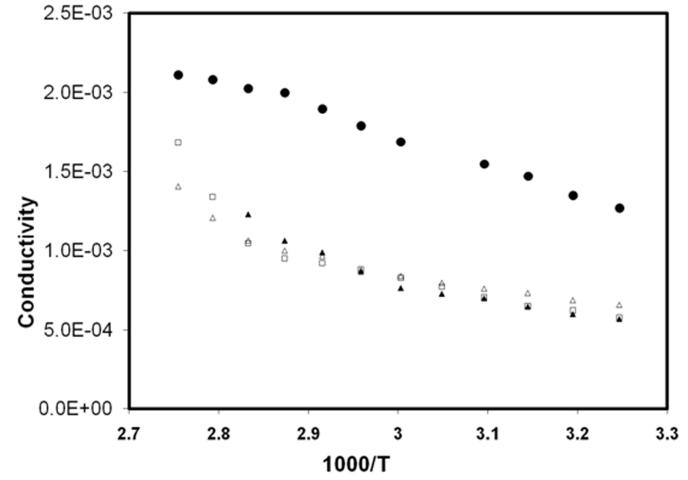

Figure 9. Temperature dependence electrical conductivity of (PVA: PVK): $\mathrm{CH}_{3} \mathrm{COONH}_{4}$ : EC system at $(\square) 0.2,(\bullet) 0.4,(\boldsymbol{\bullet}) 0.6$ and $(\rho) 0.8$ mole Ammonium acetate concentration.

$$
\begin{gathered}
\sigma=\sigma_{0} \exp \left(-\frac{E_{a}}{k T}\right) \\
\sigma=\sigma_{0} T^{-1 / 2} \exp \left(-\frac{E_{a}}{T-T_{0}}\right)
\end{gathered}
$$

where $\sigma_{0}$ is the pre-exponential factor, $E_{a}$ the activation energy, $\mathrm{K}$ is the Boltzmann constant and $\mathrm{T}_{0}=\mathrm{T}_{\mathrm{g}}-60^{\circ} \mathrm{C}$. It is interesting to note that the end point of first Arrhenius region shifts to higher temperatures with increase of salt content in blend electrolyte. This is probably due to enhanced compatibility among the polymer components in the present of higher salt content as also observed during structural characterization.

\subsection{A. C. Conductivity}

Figure 10 shows the variation of a.c. conductivity of mixed conducting system for different salt molarities. The values of a.c. conductivity were obtained with the help of dielectric permittivity $\left(\varepsilon^{\prime}\right)$ and loss tangent $(\tan \delta)$ data using the relation:

$$
\sigma_{a c}=\varepsilon^{\prime} \varepsilon_{0} \omega \tan \delta
$$

where $\varepsilon_{0}$ is the vacuum permittivity and $\omega$ the angular

\begin{tabular}{|c|c|c|c|}
\hline Name of the samples & $\sigma_{0}(\mathrm{~S} / \mathrm{cm})$ & $\mathbf{A}$ & $\mathbf{p}$ \\
\hline PVA:DMSO casted $0.2 \mathrm{M} \mathrm{CH}_{3} \mathrm{COONH}_{4}$ electrolyte & $7.83 \times 10^{-4}$ & 0.030 & 0.662 \\
\hline PVA:DMSO casted $0.4 \mathrm{M} \mathrm{CH}_{3} \mathrm{COONH}_{4}$ electrolyte & $1.1 \times 10^{-3}$ & 0.033 & 0.825 \\
\hline PVA:DMSO casted $0.6 \mathrm{M} \mathrm{CH}_{3} \mathrm{COONH}_{4}$ electrolyte & $5.5 \times 10^{-4}$ & 0.026 & 0.505 \\
\hline PVA:PVK:EC: $\mathrm{CH}_{3} \mathrm{COONH}_{4}(0.2 \mathrm{M})$ composite electrolyte & $5.5 \times 10^{-4}$ & 0.024 & 0.708 \\
\hline PVA:PVK:EC: $\mathrm{CH}_{3} \mathrm{COONH}_{4}(0.4 \mathrm{M})$ composite electrolyte & $1.27 \times 10^{-3}$ & 0.046 & 0.805 \\
\hline PVA:PVK:EC: $\mathrm{CH}_{3} \mathrm{COONH}_{4}(0.6 \mathrm{M})$ composite electrolyte & $5 \times 10^{-4}$ & 0.026 & 0.640 \\
\hline PVA:PVK:EC: $\mathrm{CH}_{3} \mathrm{COONH}_{4}(0.8 \mathrm{M})$ composite electrolyte & $6.2 \times 10^{-4}$ & 0.041 & 0.408 \\
\hline
\end{tabular}
frequency.

Table 1. Values of $\sigma_{0,}$ A and p for pristine electrolytes and PVA: PVK: EC composite electrolyte with different $\mathrm{CH}_{3} \mathrm{COONH}_{4}$ salt concentration. 


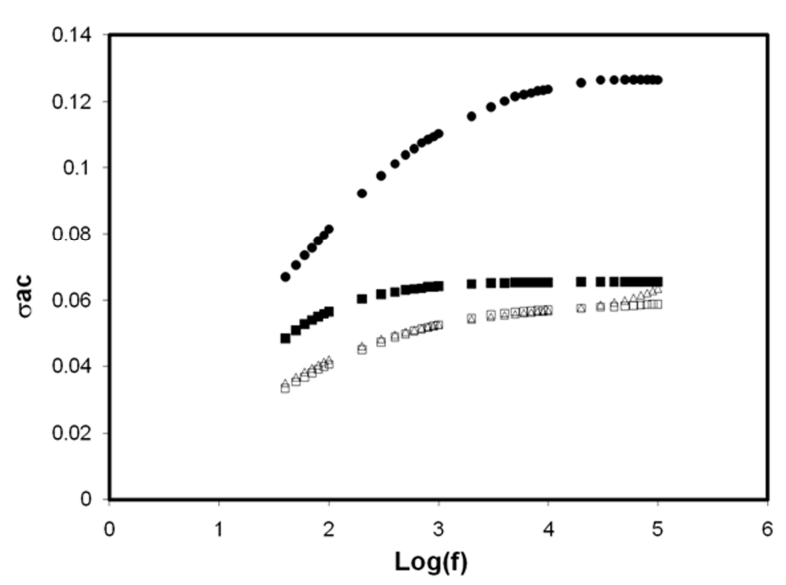

Figure 10. Variation of a.c. conductivity with frequency for mixed conducting system for different salt molarties containing $(\square) 0.2 M$, (•) 0.4 $M$, ( $\rho) 0.6 \mathrm{M}$ and (口) $0.8 \mathrm{M}$

It is apparent from figure 10 that a.c. conductivity increases with frequency in the low frequency regime followed by a nearly frequency independent behavior at high frequencies. The increasing conductivity behavior is connected to the electrode- electrolyte phenomena i.e. it results from electrode polarization effect [27] while saturation like behavior results from failure of hopping of ions from one side to another with increasing frequency. The overall a.c. conductivity can be best described by Jonscher's power law relation:

$$
\sigma_{a c}(\omega)=\sigma_{d c}+A \omega^{p}
$$

where $\sigma_{\mathrm{dc}}$ is bulk d.c. conductivity (obtained from extrapolation of plateau regime to zero frequency). A the pre-exponential factor, $\mathrm{p}$ the fraction exponent lying between 0 and 1 and $\omega$ the angular frequency. The value of parameters $\sigma_{\mathrm{dc}}, \mathrm{A}$ and $\mathrm{p}$ were obtained by curve fitting and have been shown in table 1 . Generally, for ionic conductors the power fraction exponent (p) can be between 1 and 0.5 indicating ideal long range pathway and diffusion limited hopping (tortuous pathway) respectively. The estimated parameter values (table 1) suggest that the overall frequency response can be well described by jump relaxation model [28] where ionic conduction is caused by translation of mobile ions and localised hopping (hopping takes place in both space and time). Actually when a mobile ion hops from any site $\mathrm{X}$ to a neighboring site $\mathrm{Y}$ there exist relaxation processes. After going to site $\mathrm{Y}$ the ion may hop back. Alternatively, it is possible that before the ion hops back, the surrounding of new site may relax in such a way that ion may find its new quasi permanent place. Such a process will ultimately affect conductivity positively. Thus overall behavior follows universal dynamic process observed in disordered materials like in the present system.

\section{Conclusion}

Polyvinyl alcohol: polyvinyl carbazole blend based mixed ion- electron conductors were prepared by solvent casting technique. Complex formation of PVA: $\mathrm{PVK}$ : $\mathrm{CH}_{3} \mathrm{COONH}_{4}$ : EC system has been confirmed through XRD, optical microscopy and FTIR studies besides improvement in system morphology. High ionic transference number $(\sim 0.8)$ observed in Wagner polarization studies indicate dominance of ionic charge transport over the electronic counterpart. The ionic conductivity of mixed conducting system is seen to improve at room temperature with an optimum value $1.27 \times 10^{-3} \mathrm{~S} / \mathrm{cm}$ for 0.4 mole ammonium acetate concentration. Temperature dependence of conductivity is best described by combination of Arrhenius and VTF behavior with improvement in Arrhenius region with increasing salt content in composite system. The ac behavior of conductivity is seen to obey Jonscher's power law behavior. $\mathrm{C}-\mathrm{V}$ data indicates best cyclic reversibility for composite system containing $0.4 \mathrm{M}$ salt besides improvement in electrochemical stability with optimum electrochemical window ranging from $-0.366 \mathrm{~V}$ to $+1.633 \mathrm{~V}$. Since the composite system for $0.4 \mathrm{M}$ salt exhibit maximum conductivity and good electrochemical window, this can be used as a good electrode material/electrolyte for batteries and other electrochemical devices.

\section{References}

[1] J. R. MacCallum, C. A. Vincent, (eds), "Polymer Electrolyte Reviews," London: Elsevier Applied Science Publisher, pp. $1-2,1989$.

[2] F. M. Gray, "Solid Polymer electrolytes- Fundamentals and Technological Application,” New York: VCH, 1991.

[3] S. Chandra, S. S. Sekhon, and N. Arora, Ionics, vol.6, p.p.112, 2000 .

[4] R. C. Agrawal, and G. P. Pandey, J Phys. D: Appl. Physics, vol.41, 223001, 2008.

[5] J. A. Siddiqui, and P. V. Wright, Faraday Discuss. Chem. Soc., vol.88, pp.113, 1989.

[6] O. Inganas, Br. Polym. J., vol. 20, pp.233, 1988.

[7] M. M. Lerner, L. J. Lyons, J. J. Tonge, and D. F. Shriver, Polym. Prepr., vol. 1, pp. 435,1989.

[8] M. G. Minett, and J. R. Owen, Solid State Ionics, vol.1192, 28, 1988.

[9] K. Conheeney, and P. V. Wright, Polym. Commun., vol. 27, pp. 364, 1986.

[10] J. H. Choi, K. W. Park, H. K. Lee, Y. M. Kim, J. S. Lee, and Y. E. Sung, Electrochimica Acta, vol. 48, pp. 2781, 2003.

[11] M. S. Michael, and R. S. Prabaharan, Journal of Power Source, vol. 136, pp. 408, 2004.

[12] S. K. Patel, R. B. Patel, A. Awadhia, N. Chand, and S. L. Agrawal, Pramana- Journal of physics, vol. 69, pp. 467, 2007.

[13] M. Ramrakhiani, International journal of Luminescence and Application, vol. 3, pp. 15, 2013. 
[14] P. Thanigainathan, and C. Paramasivan, International Nano Letters, 10.1186/2228-5326-3-9.

[15] S. L. Agrawal, and P. K. Shukla, Ionics, vol. 6, pp. 312, 2000.

[16] S. L. Agrawal, and A. Awadhia, Bull. Mater. Sci, vol. 27, pp. 523, 2004.

[17] S. Selvasekarpandiana, G. Hirankumara, J. Kawamura, N. Kuwata, and T. Hattori, Mater. Lett., vol. 59, pp. 2741, 2005.

[18] N. Chand, N. Rai, S. L. Agrawal and S. K. Patel, Bull. Mater Sci., vol. 34, pp. 1297, 2011.

[19] A. Awadhia, and S. L. Agrawal, Solid State Ionics, vol. 178, pp. 951, 2007.

[20] C. A. Finch (ed.), Polyvinyl Alcohol Properties and Applications (Bristol: John Wiley \& Sons), 1973.

[21] K.Gong, and L. Zong, MRS Conf on Solid State Ionics (Boston: preprint), 1988.

[22] N. Kubota, S. Fujii, N. Tatsumoto, and T. Sano, Journal of Applied Polymer Science, vol. 83, pp. 2655, 2002.
[23] A. Awadhia, S. K. Patel, R. B. Patel, and S. L. Agrawal, Electroactive Polymers: Materials and Devices edited by N. Khare, S. A. Hasmi, A. Chandra, and A. Chandra Series ed. S. Chandra (New Delhi: Allied Publishers) pp. 115-121, 2006.

[24] M. Deepa N. Sharma, P. Varshney, R. Chandra, and S. A. Agnihotri, Ion Conducting Materials: Theory and Applications edited by A. R. Kulkarni, and P.Gopalan, (New Delhi: Narosa Publishing House) pp. 74-81, 2001.

[25] S. S. Sekhon, N. Arora, B. Singh, and S. Chandra, J. of Materials Science, vol. 37, pp. 2159, 2002.

[26] J. R. Macdonald, "Impedance Spectroscopy Emphasizing Solid Materials and Systems," New York: Wiley, 1987.

[27] S. L. Agrawal, M. Singh, M. M. Dwivedi, M. Tripathi, and K., Pandey, J. Materials Sci., vol. 44, pp. 6068, 2009.

[28] K. Funke, “Jump Relaxation in Solid Electrolytes," Progress in Solid State Chemistry, vol. 22, pp. 111, 1992 